\title{
Did Analysts Learn? -- A Rationality Analysis
}

\author{
Cheng-Huei Chiao \\ Missouri Western State University \\ Chiou-Fa Lin \\ National Formosa University \\ Jun Wang \\ University of Montevallo
}

\begin{abstract}
In this study we examine changes of behaviors of financial analysts in earnings forecasts in the aftermath of the stock market price boom led by high tech related shares, which ended in early year 2000. We have found that, in the period prior to year 2000, financial analysts were in general over-optimistic and underreactive, meaning slow in correcting previous errors, in earnings forecasts. These behaviors were especially profound for firms in the high tech related sectors. But these phenomena went into reversal in the post-2000 period. Specifically, we have found that analysts became over-pessimistic, and were especially so for high tech firms. Analysts also tended to be much less under-reactive and showed stronger proclivity to overreact. The concept of behavioral instability and the statistical techniques for testing behavioral changes in analysts' earnings forecasts explained in this study have useful applications and implications to research work on broader financial topics.
\end{abstract}

\section{INTRODUCTION}

Much of research, excluding event studies, on analysts' behaviors has been conducted, explicitly or implicitly, based on the (stationarity) assumption that analysts maintain the same behavioral mode throughout whatever the data window the researchers happened to choose for the analysis. The issue of non-stationarity involving an event not widely recognized or suspected by researchers but having caused substantial or dramatic changes in analysts' behaviors requires more attention in the literature. This paper in part fills this need.

1. In this study we adopt the "rationality" concept and methodology developed by Keane and Runkle (1998) for the measurements and analysis of accuracy of analysts' earnings forecasts.

2. Our current study intends to emphasize on individual analysts' behaviors, their characterizations and dynamics, and the nature of contributing factors.

3. In addition, we noticed that not enough attention in the literature has been placed on the relations between analysts' performance and the characteristics of the firms that they follow. We hence developed correlation measures to study such relations. These relations, provide important insights into analysts' firm-dependent forecasting behaviors. 
In this paper, we document and examine analysts' pre- versus post-year-2000 behaviors in earnings forecasts and assess the extent of validity of the behavioral paradigms. We also look into the potential effects of new securities laws, namely, Sarbanes-Oxley Act and Regulation Fair Disclosure, both of which were enacted in early 2000 's.

\section{Highlights of Our Findings}

First, we have found that analysts appear to be, on average, biased upward in their earnings forecasts during the pre- 2000 period. These upward biases are characterized by extreme optimistic estimates posted by a small fraction of analysts, and are especially so for high tech firms. On the other hand, in the post2000 period, the distributions of forecast errors of individual analysts shift strongly to the down side, and this observation is even more striking on results tabulated by firms, implying that factors associated with firms surpass those associated with analysts in driving this behavioral change.

Second, analysts have been founding a roughly 70 to 30 ratio to be too slow (underreacting) versus too fast (overreacting) in correcting their previous forecast errors. But the exact magnitudes and ratios of the under-reaction to over-reaction are milder during the post-2000 period than during the pre-2000 period. Again, firm factors are stronger than analyst factors in driving the two mis-reactions.

Third, it has been found that in majority (about $75 \%$ ) of cases an analyst who makes a large positive (negative) forecast error in the past quarter tends to shift his forecast number downward (upward), relative to the consensus forecast for the current (on-going) quarter. This seemingly rational behavior applies to both sectors and both periods.

Fourth, we have found that, for the pre-2000 period, firms that have very large earnings disappointments (meaning analysts' earnings forecasts being too high, ex post) are also the firms to which analysts, on average, under-react the most. On the other hand, firms with largest positive earnings surprises, over time, are the ones revealing the strongest overreactions from analysts This observation seems to resonate with the findings reported by Easterwood and Nutt (1999) that analysts under-react to bad earnings news and over-react to good earnings news. Interestingly, this phenomenon became statistically insignificant for the high-tech sector, and even reversed itself mildly for the non-high-tech sector, during the post-2000 era.

Fifth, we have found that for high-tech stocks and for both pre- and post-2000 periods an ex post over-optimistic analyst tends to shift his next forecast number in the direction opposite to his deviation from the consensus forecast in the previous quarter (i.e., uncomfortable to be away from the herd, thus a herd follower or trend chaser). But the opposite holds true for the non-high-tech sector (again for both pre- and post-2000 eras). Further, a herd follower also tends to be slow in reacting to previous forecast errors (i.e., unsure about how to react) and this phenomenon appears in both non-high-tech and high-tech sectors and for both pre- and post-2000 periods. These observations suggest that in the community of financial analysts, over-optimists, slow movers, and herd followers often feature themselves in a cluster of analysts who adopt a sub-culture of their own.

The organization of the remainder of this paper is as follows: Section 2 discusses the data structure and sample constraints. Section 3 lays out the mathematical model and the estimation procedure. Section 4 reports empirical results from rationality tests for the 1992-1999 and 2000-2007 periods separately. Section 5 explains the empirical findings from various perspectives. Section 6 concludes the paper by summarizing the findings and pointing out the implications of this study to broader financial research.

\section{Data Structure}

The data for our study comes from the intersection of (a) the Institutional Brokers Estimate System (IBES) files and (b) the Center for Research in Security Prices (CRSP) files. The former contains earnings forecasts data from IBES and the latter the common stock share price data from the CRSP. The sample covers the period from the first quarter of 1992 through the fourth quarter of 2007, involving 64 consecutive quarters of data.

To make the data suitable for a systematic study, we performed the following data standardization on our data files. 
Second, since the main earnings forecast files that the IBES provides are stock-split adjusted, we constructed a comparable series of stock-split adjusted per share stock prices by adjusting the original (unadjusted) per share stock price file from the CRSP using the FACSHR sub-file. The latter file contains stock split records for all firms included in the data set and over the entire sample period. This approach has an advantage over using the raw unadjusted data for both earnings forecasts and prices. This is because it can effectively avoid the mismatching of earnings numbers and per share stock prices when a stock split occurs somewhere between the beginning and the end of a quarter.

Third, because of the nature of the AR (1) process, which characterizes the earnings forecasts as a series over time, in our rationality tests we needed to stabilize the relationship between earnings growth rate and per share stock price appreciation rate, for each individual analyst-firm pair over the sample period. We realized that earnings grew at a rate much slower than that of stock price appreciation for most firms over the sample period of years 1992-1999; that is, the value of the price/earnings ratio, in general, expanded considerably over the sample period. On the other hand, the situation was more or less reversed in the period of years 2000-2007. Without a time series trend adjustment on the value of the earnings/price ratio, our earnings standardization scheme (dividing earnings per share by per share stock price) could have an unintended effect; it artificially imposes a downward (or upward) trend and a seemingly convergent pattern toward (or away from) zero on the time series of forecast errors for many firms and distorts the outcomes of the empirical tests.

For our comparative analysis of non-high-tech versus high-tech firms, we separated the data for years 1992-2007 into two segments, each eight-year in length, that is, 1992-1999 versus 2000-2007. The separation point was selected to coincide with the end of the high-tech stock market boom, which occurred in early year 2000. We then identified firms, which were in the top 10th percentile of stock price total returns in the period from 1/1/1998 through 3/31/2000. These firms were then tracked by the first three digits of their SIC codes. We calculated the proportion of the firms within each three-digit SIC code which are members of the top 10-percentile group. We then identified eleven SIC groups, which only have a one-percent chance or less to have as high a proportion of firms falling in the top $10 \%$ group under the standard binomial probability model. More specifically, we note that vast majority of the firms in the identified groups are in the industries closely related to internet, telecommunication, computer, or biomedical products. The proportion of firms in this so-called "high-tech" sector comprises $27 \%$ of all firms in our sample for the period 01/1998 - 03/2000. We constructed analysis, as described in the following sections, for each of the two eight-year periods and, within each period, for high-tech and nonhigh-tech firms separately. We thus have $2 \times 2=4$ sets of statistical estimation results.

Mean values of individual analysts' earnings forecast errors (FE) and values of deviation from the consensus (DE) in our sample for the two time segments and the two sectors (non-high-tech versus hightech) are provided in Table 1. The total number of analyst-firm-quarter triplets is 306,570 for the 16-year sample period, and the number of analyst-firm pairs is 21,150 ; counted separately from the two eight-year time segments. The number of analyst-firm pairs, $\mathrm{N}$, for each of the $2 \times 2$ categories is listed in Table 1 .

The positive mean values of forecast errors (FE's) for both non-high-tech and high-tech sector in the pre-2000 period, as reported in Table 1, suggest an overall upward bias in analysts' forecasts. It is consistent with the findings reported in, for instance, Easterwood and Nutt (1999) and Tamura (2002). However, the situation reversed itself, in the high-tech sector, in the post-2000 period. It hints at a potential reversal in analysts' mind set and their forecasting strategies. The generally negative values of the variable $\mathrm{DE}_{t}$ suggest that our data trimming process has in fact removed more of the upwardly biased forecasts than the downwardly biased forecasts. 


\section{TABLE 1 \\ MEAN VALUES OF EARNINGS FORECAST ERRORS AND DEVIATIONS FROM THE CONSENSUS}

1. $\mathrm{FE}_{\mathrm{t}}$ is the forecast value minus the actual earning, at time $\mathrm{t}$ (quarter $\mathrm{t}$ ), and divided by the stock price at the closing of the last day of the previous quarter. The stock price has been adjusted for the long-term earnings/price ratio time trend to equalize the scale factor throughout a firm. $\mathrm{DE}_{\mathrm{t}}$ is the forecast value minus the consensus earnings forecast at time $\mathrm{t}$, standardized similarly as that for $\mathrm{FE}_{\mathrm{t}}$. The mean, standard deviation and all other statistics are computed (not shown below) for the sample period that begins in the first quarter of 1992 to the fourth quarter of 2007. Observations of $\mathrm{FE}_{\mathrm{t}}$ with absolute value exceeding 1.0 are deleted from the sample due to their likelihood of being data errors or extreme observations. The corresponding $\mathrm{DE}_{\mathrm{t}}$ observations are also removed from our sample. Other data trimming requirements are provided in the text.

2. The data variable $\mathrm{FE}_{\mathrm{t}}$ spans from the first quarter through the last quarter of our sample period. The total number of quarter-analyst-firm triplets in our sample is 306,570 .

3. The negative mean values for the variable $\mathrm{DE}_{\mathrm{t}}$ shown below are because of the data trimming scheme explained earlier in Section 2. The consensus forecasts which are used to subtract from an analyst's forecasts in order to compute $\mathrm{DE}_{\mathrm{t}}$ were compiled by IBES and include all participating analysts' forecasts.

4. The mean values provided in the table below are for the variables calculated on individual analyst-firm pairs. The value $\mathrm{N}$ is the number of analyst-firm pairs used to compute the mean value of the variable, $\mathrm{FE}_{\mathrm{t}}$ or $\mathrm{DE}_{\mathrm{t}}$.

Mean values of variables calculated on individual analyst-firm pairs

\begin{tabular}{ccc|cc}
\hline & \multicolumn{2}{c|}{$1992-1999$} & \multicolumn{2}{c}{$2000-2007$} \\
\cline { 2 - 5 } Variable & Non-high-tech & High-tech & Non-high-tech & High-tech \\
\hline $\mathrm{FE}_{\mathrm{t}}$ & 0.00108 & 0.00154 & 0.00090 & -0.00036 \\
$\mathrm{DE}_{\mathrm{t}}$ & -0.00050 & -0.00061 & -0.00041 & -0.00021 \\
$\mathrm{~N}$ & 7,280 & 2,188 & 7,966 & 3,671 \\
\hline
\end{tabular}

\section{The Model and the Estimation Procedure}

In Subsection 3.1, we report on reformulated rationality tests, for both gross forecast errors and deviations from consensus forecasts, focusing on the two key parameters, unbiasedness and efficiency, in a first-order autoregressive, AR (1), time series model. This reformulation provides a framework for broad-based statistical characterizations of individual analysts' behaviors and facilitates the construction and operation of a systematic testing procedure. Subsection 3.2 suggests a two-way fixed effect model to alleviate the influences of cross-sectional correlation in forecast errors among analysts and across firms, to the variables under study.

\subsection{Equations for Rationality Tests}

Suppose that analyst $j$ makes a forecast at time $t$ of the upcoming per share earnings number, EPS, of firm $k$ to be reported at time $t+1$. We shall denote that forecast as ${ }_{t} E P S_{j, t+1}^{k}$. If the analyst is rational, the forecast must be equal to the mathematical expectation of the upcoming reported EPS, i.e. $E P S_{t+1}^{k}$, conditional on the information set available to analyst $\mathrm{j}$ at time $\mathrm{t}$. In other words, ${ }_{t} E P S_{j, t+1}^{k}=$ 
$\mathrm{E}\left(E P S_{t+1}^{k} \mid \mathrm{I}_{\mathrm{j}, \mathrm{t}}\right)$, where $E P S_{t+1}^{k}$ as noted above is the EPS number to be observed, while $\mathrm{I}_{\mathrm{j}, \mathrm{t}}$ is the information set available to analyst $j$ at time $t$, and $\mathrm{E}$ is the mathematical expectation operator.

To eliminate hereroskedasticity over time in forecast errors, we standardize the variables FE and DE by the per share stock price, which is de-trended on the time series of earnings/price ratio, at the closing of the last day of the previous quarter. In algebraic form, they are

$$
\begin{aligned}
& { }_{t} F E_{j, t+1}^{k}=\frac{{ }_{t} E P S_{j, t+1}^{k}-E P S_{t+1}^{k}}{\bar{P}_{t}{ }^{k}}, \\
& { }_{t} D E_{j, t+1}^{k}=\frac{{ }_{t} E P S_{j, t+1}^{k}-{ }_{t} E P S_{c, t+1}^{k}}{\bar{P}_{t}{ }^{k}},
\end{aligned}
$$

where ${ }_{t} E P S_{c, t+1}^{k}$ is the consensus forecast (i.e., mean value of forecasts from all participating analysts for firm $k$ at time $t$ ), compiled by the IBES. In addition,

$\bar{P}_{t}^{k}=P_{t}^{k} \times f_{t}^{k}$

$f_{t}^{k}=\hat{y}_{t}^{k} / \hat{y}_{m}^{k}, \mathrm{t}=1,2, \ldots, 32$, for each of the eight-year time series, subject to availability of data, where $m$ : midpoint of sample period;

$y_{t}^{k}=a_{0, k}+a_{1, k} \mathrm{t}+\varepsilon_{t}^{k}$,

which is a time trend regression model. Further,

$y_{t}^{k}=\left(E P S_{t}^{k} / P_{t}^{k}\right)$

in which $P_{t}^{k}$ is the observed per share price, and

$\hat{y}_{t}^{k}=\hat{a}_{0, k}+\hat{a}_{1, k} \mathbf{t}$,

where the symbol "^" signifies the "estimated" parameter value.

Here the two terms FE and DE, as defined above, are in opposite sign to a conventional definition used in many studies in the literature. is

We now turn to the test equation suggested by Keane and Runkle (1998, p. 773, equation (2)), which

$$
E P S_{t+1}^{k}=\beta_{0}+\beta_{1} E_{t} P S_{j, t+1}^{k}+\beta_{2} \mathrm{X}_{\mathrm{j}, \mathrm{t}}+\varepsilon_{j, t+1}^{k},
$$

where $\mathrm{X}_{\mathrm{j}, \mathrm{t}}$ represents some auxiliary information related to the forecast process. It can be: previous forecast errors; reported EPS numbers in the past; forecasts made by other analysts; current macroeconomic forecasts; and so on. The term $\varepsilon_{j, t+1}^{k}$ represents a random error. The unbiasedness 
condition in the rationality test requires that $\beta_{0}=0$ and $\beta_{1}=1$, while the efficiency condition requires that $\beta_{2}=0$.

Set $\mathrm{X}_{\mathrm{j}, \mathrm{t}}=\operatorname{EPS}_{t}^{k}-_{t-1}$ EPS $_{j, t}^{k}, \beta_{1}=1$, and through some algebraic steps, we can transform equation (1) into the following equations:

$$
\begin{gathered}
{ }_{t} F E_{j, t+1}^{k}=\alpha_{0}+\alpha_{1}\left({ }_{t-1} F E_{j, t}^{k}\right)+\eta_{j, t+1}^{k} \text {, or } \\
{ }_{t} F E_{j, t+1}^{k}=\left(1-\alpha_{1}\right) \mu+\alpha_{1}\left({ }_{t-1} F E_{j, t}^{k}\right)+\eta_{j, t+1}^{k} \quad ; \text { or } \\
{ }_{t} F E_{j, t+1}^{k}-\mu=\alpha_{1}\left({ }_{t-1} F E_{j, t}^{k}-\mu\right)+\eta_{j, t+1}^{k}
\end{gathered}
$$

where $\eta_{j, t+1}^{k}$ is another variable of random error. We note that $\alpha_{0}=\left(1-\alpha_{1}\right) \mu$, or equivalently $\mu=\alpha_{0}$ $/\left(1-\alpha_{1}\right)$. Under the rationality hypothesis, the unbiasedness condition requires $\mu=0$, and the efficiency condition requires $\alpha_{1}=0$. To test the two conditions in any of the equations (2a), (2b) and (2c) is easier than to test the three conditions imposed in equation (1). Equations (2a), (2b), and (2c) are interchangeable and the choice depends on the computational task at hand.

Besides an analyst's forecast errors in the previous period, an analyst's past deviation from the consensus forecast, indicative of the analyst's relative optimism/pessimism, can be added to the test equation as another auxiliary variable for further testing of rationality. This leads us to the following equation:

$$
\begin{aligned}
& { }_{t} F E_{j, t+1}^{k}=\alpha_{0}+\alpha_{1}\left({ }_{t-1} F E_{j, t}^{k}\right)+\alpha_{2}\left(_{t-1} D E_{j, t}^{k}-v\right)+\delta_{j, t+1}^{k}, \quad \text { or } \\
& { }_{t} F E_{j, t+1}^{k}=\left(1-\alpha_{1}\right) \mu+\alpha_{1}\left(_{t-1} F E_{j, t}^{k}\right)+\alpha_{2}\left(_{t-1} D E_{j, t}^{k}-v\right)+\delta_{j, t+1}^{k}, \text { or } \\
& { }_{t} F E_{j, t+1}^{k}-\mu=\alpha_{1}\left({ }_{t-1} F E_{j, t}^{k}-\mu\right)+\alpha_{2}\left({ }_{t-1} D E_{j, t}^{k}-v\right)+\delta_{j, t+1}^{k}
\end{aligned}
$$

where $v$ is the mean level of the variable $\mathrm{DE}$, and $\delta_{j, t+1}^{k}$ is another random error term. Under the rationality assumption, in addition to the joint condition $\mu=\alpha_{1}=0$, an extra condition, $\alpha_{2}=0$, is required.

However, because of uneven information access; differential analytic skills; heterogeneous incentive structures; and varying degrees of corporate earnings management, diverse opinions among analysts are to be expected. Whether the formation process of an analyst's expectations meets the two rationality requirements can be further tested on the DE variable. This set of supplementary tests are especially important in examining analysts' tendency to follow the leaders [Cooper, Day and Lewis (1999), and Welch (2000)] or their ability to stay firm holding on to their own convictions. Following a similar process of algebraic steps as for equations $(3 a)-(3 c)$, we constructed the following equations.

$$
\begin{aligned}
& { }_{t} D E_{j, t+1}^{k}=\gamma_{0}+\gamma_{1}\left(_{t-1} F E_{j, t}^{k}-\mu\right)+\gamma_{2}\left({ }_{t-1} D E_{j, t}^{k}\right)+v_{j, t+1}^{k}, \text { or } \\
& { }_{t} D E_{j, t+1}^{k}=\left(1-\gamma_{2}\right) v+\gamma_{1}\left({ }_{t-1} F E_{j, t}^{k}-\mu\right)+\gamma_{2}\left({ }_{t-1} D E_{j, t}^{k}\right)+v_{j, t+1}^{k}, \text { or } \\
& { }_{t} D E_{j, t+1}^{k}-v=\gamma_{1}\left({ }_{t-1} F E_{j, t}^{k}-\mu\right)+\gamma_{2}\left({ }_{t-1} D E_{j, t}^{k}-v\right)+v_{j, t+1}^{k} .
\end{aligned}
$$


The requirements and interpretations of the three parameters $\gamma_{1}, \gamma_{2}$, and $v$, however, are quite different from those for the triplet $\alpha_{1}, \alpha_{2}$, and $\mu$ in equations (3a), (3b) and (3c). Since the variable DE measures the deviation from the consensus forecast, and there is no guarantee that the consensus forecast itself conforms to the rationality model, we cannot impose unconditionally the requirements of $\gamma_{1}=\gamma_{2}=$ $\nu=0$ in the rationality check. Instead, the three coefficients $\gamma_{1}, \gamma_{2}$, and $v$ in equations (4a), (4b), and (4c) represent an analyst's potential aptitude or tendency in counteracting a bias and/or correcting the inefficiency built into the consensus forecasts. The requirements of $\gamma_{1}=\gamma_{2}=v=0$ in conformity to rationality will be sensible only when we can first rectify rationality on the consensus.

More importantly, equations (4a), (4b) and (4c) provide us with a tool to investigate the various aspects of analysts' behavioral patterns in relation to consensus forecasts. The results have significant ramifications on analysts' herding behaviors; tendency to over-react or under-react relative to his (her) peers; and proclivity toward over-optimism or over-pessimism, as will be explained in Sections 3 and 4.

\section{Two-way Fixed Effect Model}

Cross-sectional correlation often exists among analysts and across firms in earnings forecast errors. It poses an econometric difficulty in rationality tests.

We took a different path. We looked for a data structure, which is least susceptible to the problem in question. This led us to work on data disaggregated into analyst-firm pairs. Regression estimates on the variables within an analyst-firm pair are seen to be statistically unbiased and consistent, though not efficient. They can substantially mitigate the difficulty in hand.

Parameter estimates from all analyst-firm pairs are organized and analyzed using a two-way fixed effect model. An estimate of a parameter, for example, $\mu$, for a particular analyst-firm pair, say, analyst $\mathrm{j}$ and firm $\mathrm{k}$, denoted by $\mu_{j, k}$, can be statistically characterized as follows:

$$
\mu_{j, k}=\bar{\mu}+\mu_{j}+\mu_{k}+\varepsilon_{j, k}(\mu)
$$

where $\bar{\mu}$ is the grand average of the estimates $\mu_{j, k}$ from all analyst-firm pairs, $\mu_{j}$ is the average of $\mu_{j, k}$, minus $\bar{\mu}$, for analyst $\mathrm{j}$ across all of the firms the analyst follows, $\mu_{k}$ is the average of $\mu_{j, k}$, minus $\bar{\mu}$, across all analysts who cover firm $\mathrm{k}$, and $\varepsilon_{j, k}(\mu)$ is a random error term designated for the parameter $\mu$. Factors affecting forecast errors associated with an analyst, and a firm, are captured by $\mu_{j}$ and $\mu_{k}$ respectively. We define:

$$
\begin{aligned}
& \mu_{j}^{*}=\bar{\mu}+\mu_{j}, \text { and } \\
& \mu_{k}^{*}=\bar{\mu}+\mu_{k},
\end{aligned}
$$

where $\mu_{j}{ }^{*}$ and $\mu_{k}{ }^{*}$ represent the average levels of the value of $\mu$ for analyst $j$, and firm $k$, respectively.

As such, the standard deviation of the error term $\varepsilon_{j, k}(\mu)$ serves as a base for the significance tests on $\mu_{j}$ and $\mu_{k}$. The same model applies to all other characterization (vis-à-vis rationality) parameters in our study. Besides, this approach, based on disaggregated data, provides new insights into the individualism among analysts and across firms. 


\section{Empirical Results}

\section{Basic Results}

We start our analysis by running estimation and testing procedures at three levels of data segregation. The first is to lump all data from analysts and firms into a single pool. The second is to separate data by individual analysts. The third is to divide the data by analyst-firm combinations. Analysis on the first and the second levels is to provide a comparison to results reported in the extant literature, while the analysis at the third level is to prepare for our primary task.

As an illustration, results from regression analysis at the three data levels, for non-high-tech firms in the period 1992-1999, are reported in Table 2. Each of the three panels represents a data level, starting from the top with the first data level. Three regression models, with varying choices of predictor variables, are listed as FE1, FE2, and FE3 for the first data level. Estimation results for FE1 show definitely, significantly positive values of $\mu$ and $\alpha_{1}$; providing a strong indication that, overall, analysts' forecasts are upwardly biased and have a tendency to under-react to past earnings forecast errors. This is a typical finding in the extant literature.

The estimation results for model FE2 show that influences on FE from lagged DE, as represented by $\alpha_{2}$, carry a positive sign with $\mathrm{t}=7.35$. It implies that an excessively optimistic opinion relative to the analyst consensus this quarter tends to carry an upward momentum on FE into the next quarter.

For model FE3, which contains both lagged FE's and DE's as predictor variables, we observe an estimation result on $\alpha_{1}$ similar to that in FE1, but a borderline negative parameter value in $\alpha_{2}$. This latter finding hints at an interaction between FE and DE in predicting future FE's.

At the second level of data segregation, the results from models FE4, FE5, and FE6, which follow the same formulation as FE1, FE2, and FE3, are similar, except for $\alpha_{2}$ on FE5. Finally, when we come down to the third level of data separation, the magnitudes of the parameter values tend to be smaller, though not statistically less significant. But it basically tells the same story.

\section{TABLE 2}

\section{TEST OF RATIONALITY IN EARNINGS FORECASTS (NINE EQUATIONS FOR 1992-1999 NON-HIGH-TECH SECTOR)}

The term ${ }_{t} F E_{j, t+1}^{k}$ is the forecast error made by analyst $j$ at time $t$, for the earnings of firm $k$ at time $t+1$. Similarly, ${ }_{\imath} D E_{j, t+1}^{k}$ is the deviation of forecast number from the consensus estimate made by analyst $j$ at time $t$, for the earnings of firm $k$ at time $t+1$. (See more detailed definitions of $F E$ 's and $D E$ 's in the notes for Table 1.) The values of t-ratio are placed in the parentheses under coefficients. The term $\mu$ is the mean of ${ }_{t} F E_{j, t+1}^{k}$, while $v$ is the mean of ${ }_{t} D E_{j, t+1}^{k}$. The terms $\alpha_{1}$ and $\alpha_{2}$ are regression parameters. The number of data points available for analysis, or the number of estimated equations for which the mean values are displayed, is different from case to case and is indicated on the last column under the caption $\mathrm{N}$. The number of analysts and the number of analyst-firm pairs are slightly different for each equation because of different data availability and data trimming needs; see the main text of the paper and the notes in the next few tables for more explanations. Listed in Panels B and C are the estimated parameter values averaged across all analysts and analyst-firm pairs, respectively. The value of t-ratio displayed in the parentheses beneath each average parameter estimate is based on the null hypothesis that the estimates involved in the averaging are statistically independent and have an expected value equal to zero. The $\mathrm{R}^{2}$ values reported in Panels $\mathrm{B}$ and $\mathrm{C}$ are the average $R^{2}$ across all estimated equations. 


\begin{tabular}{|c|c|c|c|c|c|}
\hline \multicolumn{2}{|c|}{ Model: ${ }_{t} F E_{j, t+1}^{k}=$} & $+\alpha_{1-1} F E_{j, t}^{k}$ & $+\alpha_{2}\left({ }_{t-1} D E_{j}^{k}\right.$ & \multirow[t]{2}{*}{$+\varepsilon_{j, t+1}^{k}$} & \\
\hline \multicolumn{5}{|c|}{ Panel A. Pooling all observations } & \\
\hline Model & $\mu$ & $\alpha_{1}$ & $\alpha_{2}$ & $\mathrm{R}^{2}$ & $\mathrm{~N}$ \\
\hline FE 1 & $\begin{array}{c}0.00100 \\
(14.77)\end{array}$ & $\begin{array}{c}0.21020 \\
(69.50)\end{array}$ & & 0.04282 & 107,983 \\
\hline FE 2 & $\begin{array}{c}0.00100 \\
(17.82)\end{array}$ & . & $\begin{array}{c}0.02222 \\
(7.35)\end{array}$ & 0.00050 & 107,983 \\
\hline FE 3 & $\begin{array}{r}0.00100 \\
(14.77) \\
\end{array}$ & $\begin{array}{c}0.21130 \\
(69.14) \\
\end{array}$ & $\begin{array}{c}-0.00759 \\
(-2.54) \\
\end{array}$ & 0.04288 & 107,983 \\
\hline \multicolumn{6}{|c|}{ Panel B. For each analyst } \\
\hline FE 4 & $\begin{array}{c}0.00103 \\
(8.98)\end{array}$ & $\begin{array}{c}0.16780 \\
(22.26)\end{array}$ & . & 0.10326 & 1,297 \\
\hline FE 5 & $\begin{array}{c}0.00098 \\
(9.04)\end{array}$ & . & $\begin{array}{c}-0.06652 \\
(-3.55)\end{array}$ & 0.07292 & 1,305 \\
\hline FE 6 & $\begin{array}{c}0.00100 \\
(8.37) \\
\end{array}$ & $\begin{array}{r}0.18790 \\
(23.30) \\
\end{array}$ & $\begin{array}{c}-0.14258 \\
(-4.24) \\
\end{array}$ & 0.17465 & 1,275 \\
\hline \multicolumn{6}{|c|}{ Panel C. For each analyst and firm } \\
\hline FE 7 & $\begin{array}{c}0.00100 \\
(9.05)\end{array}$ & $\begin{array}{c}0.08600 \\
(24.65)\end{array}$ & & 0.09680 & 7,162 \\
\hline FE 8 & $\begin{array}{c}0.00080 \\
(7.22)\end{array}$ & . & $\begin{array}{c}-0.08634 \\
(-9.66)\end{array}$ & 0.10421 & 7,189 \\
\hline FE 9 & $\begin{array}{c}0.00090 \\
(10.86)\end{array}$ & $\begin{array}{c}0.08950 \\
(22.83)\end{array}$ & $\begin{array}{c}-0.11811 \\
(-9.28)\end{array}$ & 0.19729 & 6,989 \\
\hline
\end{tabular}

A composite table for the parameter estimates for Model FE9, for the $2 \times 2$ data groups, defined on the analyst-firm pairs, is provided in Table 3 . Noticeable changes in parameter values from the first sample time segment to the second time segment are summarized below:

(i) The value of $\mu$ for the high-tech firms drops from 0.00150 , with $t=9.52$, in the 19921999 period, to -0.00035 , with $\mathrm{t}=-7.12$, in the $2000-2007$ period. This represents a drastic shift in analysts' overall orientation and attitude in earnings forecasting, for hightech firms, in the post-boom period. On the other hand, the estimated value of $\mu$ for nonhigh-tech firms shifts; from a strong positive value of $0.00090(t=10.86)$ in 1992-1999, to an insignificant negative value, $-0.00024(t=-0.79)$. These changes signify a strong shift in analysts' perceptions of corporate earnings in general, and their views on hightech firms in particular, after the sharp decline in prices of high-tech stocks, and the overall market as well, starting in early year 2000 .

(ii) The average estimate of $\alpha_{1}$ in the 1992-1999 period is $0.08950(\mathrm{t}=22.83)$ for non-hightech stocks and $0.10000(\mathrm{t}=13.63)$ for high-tech firms, both are strongly positive. The value of $\alpha_{1}$ drops moderately for non-high-tech firms (to 0.06360 ) and sharply for hightech firms (to 0.04900). These numbers reveal the overall under-reaction tendency; but this lethargy or slowness in correcting previous forecast errors tends to improve in the post-2000 period, especially for high-tech firms.

(iii) The values of $\alpha_{2}$ are significantly negative for both sectors in the pre-2000 period. They mean that analysts tend to take corrective measures when their estimates deviate from the consensus forecasts. But the estimate becomes an insignificant positive number for the high-tech sector, and a smaller significant negative number for the non-high-tech sector, in the post-2000 period. The changes in the estimated values of $\alpha_{2}$ signal that analysts tend to pay less attention to consensus forecasts than they used to in the pre-2000 period. 


\section{TABLE 3 \\ TEST OF RATIONALITY IN EARNINGS FORECASTS (FOUR PERIOD-SECTOR COMBINATIONS)}

The term ${ }_{t} F E_{j, t+1}^{k}$ is the forecast error made by analyst $j$ at time $t$, for the earnings of firm $k$ at time $t+1$. Similarly, ${ }_{t} D E_{j, t+1}^{k}$ is the deviation of forecast number from the consensus estimate made by analyst $j$ at time $t$, for the earnings of firm $k$ at time $t+1$. (See more detailed definitions of $F E$ 's and $D E$ 's in the notes for Table 1.) The values of t-ratio are placed in the parentheses under coefficients. The term $\mu$ is the mean of ${ }_{t} F E_{j, t+1}^{k}$, while $v$ is the mean of ${ }_{t} D E_{j, t+1}^{k}$.

The terms $\alpha_{1}$ and $\alpha_{2}$ are regression parameters. The number of data points available for analysis, or the number of estimated equations for which the mean values are displayed, is different from case to case and is indicated on the last column under the caption N. Listed in the table below are the estimated parameter values averaged across all analyst-firm pairs in each of the four period-sector combinations. The value of t-ratio in the parentheses beneath each average estimate is calculated based on the null hypothesis that the estimates for all analyst-firm pairs in each sub-sample are statistically independent and have an expected value equal to zero. The $\mathrm{R}^{2}$ values reported are the average $\mathrm{R}^{2}$ across all estimated equations.

\begin{tabular}{|c|c|c|c|c|c|c|}
\hline \multicolumn{2}{|c|}{ Model FE9: ${ }_{t} F E_{j, t+1}^{k}=$} & $\left.1-\alpha_{1}\right)+c$ & $F E_{j, t}^{k}+a$ & $\left.D E_{j, t}^{k}-v\right)$ & $\varepsilon_{j, t+1}^{k}$ & \\
\hline \multicolumn{7}{|c|}{ Average across all analyst-firm pairs } \\
\hline Period & Sector & $\mu$ & $\alpha_{1}$ & $\alpha_{2}$ & $\mathrm{R}^{2}$ & $\mathrm{~N}$ \\
\hline \multirow{2}{*}{ 1992-1999 } & Non-high-tech & $\begin{array}{c}0.00090 \\
(10.86)\end{array}$ & $\begin{array}{c}0.08950 \\
(22.83)\end{array}$ & $\begin{array}{c}-0.11811 \\
(-9.28)\end{array}$ & 0.20 & 6,989 \\
\hline & High-tech & $\begin{array}{c}0.00150 \\
(9.52)\end{array}$ & $\begin{array}{c}0.10000 \\
(13.63)\end{array}$ & $\begin{array}{c}-0.14634 \\
(-4.98)\end{array}$ & 0.21 & 2,188 \\
\hline \multirow{2}{*}{$2000-2007$} & Non-high-tech & $\begin{array}{c}-0.00024 \\
(-0.79)\end{array}$ & $\begin{array}{c}0.06360 \\
(16.84)\end{array}$ & $\begin{array}{c}-0.09714 \\
(-5.72)\end{array}$ & 0.18 & 7,527 \\
\hline & High-tech & $\begin{array}{c}-0.00035 \\
(-7.12)\end{array}$ & $\begin{array}{c}0.04900 \\
(9.03)\end{array}$ & $\begin{array}{c}0.01439 \\
(0.60)\end{array}$ & 0.20 & 3,514 \\
\hline
\end{tabular}

The results from analyzing the DE's, as presented in Table 4, again using 1992-1999 non-high-tech group as an example, show that analysts in our sample, after data trimming as reported in Section 2, have a tendency to reduce the overall upward bias represented by IBES compiled consensus forecasts. This is suggested by the negative significant value of $v$ in each of the three data segregation levels. Analysts tend to persist in their disagreement with the consensus at the pooled regression level, as supported by the significant positive values of $\gamma_{2}$ in equations DE1 and DE3. However, the strength of the persistence tends to diminish substantially at the disaggregated analyst-firm data level, such as in equations DE7 and DE9. But it is evident, from the values of $\gamma_{1}$ in all panels of Table 4 , that the effect on DE's from lagged gross forecast errors, FE's, is to steer the analyst in the direction, relative to the consensus opinion, opposite to his previous gross errors; that is, analysts appear to be concerned about their performance and 
tend to make corrections after checking the actual earnings numbers. This seemingly rational reaction has not been much noticed in the extant literature.

A table displaying the parameter estimates for Model DE9 for each of the partitioned $2 \times 2$ data segments is provided in Table 5. A noticeable change in parameter values from pre-2000 period to post2000 period is with $v$ in the high-tech sector. The value of $v$ changes from $-0.00060(t=-10.89)$ to $0.00022(\mathrm{t}=-4.03)$. This signals a reduced level of upward bias, on the part of the consensus forecasts. Furthermore, the negative values of $\gamma_{1}$ appear to maintain their strengths over both periods. As discussed earlier, this observation reveals analysts' seemingly rational reactions in correcting their forecasts, relative to the consensus after checking with actual earnings numbers. From a separate inspection of the estimates of $\gamma_{1}$ values, not displayed in Table 5 , we have found that over $75 \%$ of analysts carry negative values for each of the $2 \times 2$ data segments.

We also notice that the value of $\gamma_{2}$ for the non-high tech sector turns from significantly positive to mildly negative from the pre-2000 to the post-2000 period, while that of the high-tech sector is insignificant for both the pre- and post-2000 years. In this context, a positive value of $\gamma_{2}$ means positive persistence of the deviation from the consensus, while a negative value means the opposite.

But the inference procedure, used to produce Tables 2 and 4, and then Tables 3 and 5, is based on the assumption of cross-sectional independence of the error terms in the AR (1) equations, which we have used to characterize analysts' forecast errors. This assumption is often violated in the empirical data and poses an econometric difficulty for the analysis presented above. To mitigate the potential bias in inference arising from this issue and to extract more insights concerning analysts' behaviors from our extensive parameter estimates.

\section{TABLE 4 \\ TEST OF RATIONALITY AS REVEALED BY ANALYSTS' FORECAST DEVIATIONS FROM CONSENSUS (NINE EQUATIONS FOR 1992-1999 NON-HIGH-TECH SECTOR)}

The term ${ }_{t} F E_{j, t+1}^{k}$ is the forecast error made by analyst $j$ at time $t$, for the earnings of firm $k$ at time $t+1$. Similarly, ${ }_{t} D E_{j, t+1}^{k}$ is the deviation of forecast number from the consensus estimate made by analyst $j$ at time $t$, for the earnings of firm $k$ at time $t+1$. (See definitions of $F E$ 's and $D E$ 's in the notes for Table 1.) The values of t-ratio are in the parentheses under coefficients. The term $\mu$ is the mean of ${ }_{t} F E_{j, t+1}^{k}$, while $v$ is the mean of ${ }_{t} D E_{j, t+1}^{k}$. The terms $\gamma_{1}$ and $\gamma_{2}$ are regression parameters. See the notes for Table 2 for more detailed explanations. The number of data points involved in each equation is listed on the column under caption N. Slight variation in the number of data points within each of Panels $\mathrm{B}$ and $\mathrm{C}$ is due to varied data availability and data trimming needs.

\begin{tabular}{cccccc}
\hline Model: ${ }_{t} D E_{j, t+1}^{k}=$ & $v\left(1-\gamma_{2}\right)$ & $+\gamma_{1}\left({ }_{t-1} F E_{j, t}^{k}-\mu\right)+\gamma_{2}{ }_{t-1} D E_{j, t}^{k}+\eta_{j, t+1}^{k}$ \\
& \multicolumn{5}{c}{ Panel A. Pooling all observations } \\
\cline { 2 - 6 } Model & $\nu$ & $\gamma_{1}$ & $\gamma_{2}$ & $\mathrm{R}^{2}$ & $\mathrm{~N}$ \\
\hline DE 1 & -0.00050 &. & 0.20440 & 0.05312 & 107,983 \\
& $(-13.80)$ &. & $(77.83)$ &. & \\
DE 2 & -0.00050 & -0.04170 &. & 0.00925 & 107,983 \\
& $(-16.68)$ & $(-31.74)$ &. &. & 107,983 \\
DE 3 & -0.00050 & -0.05720 & 0.22110 & 0.07014 & \\
& $(-13.47)$ & $(-44.45)$ & $(84.09)$ &. & \\
\hline
\end{tabular}




\begin{tabular}{|c|c|c|c|c|c|}
\hline \multirow[b]{2}{*}{ DE 4} & \multicolumn{4}{|c|}{ Panel B. For each analyst } & \multirow[b]{2}{*}{1,307} \\
\hline & $\begin{array}{c}-0.00056 \\
(-9.00)\end{array}$ & & $\begin{array}{c}0.08160 \\
(12.24)\end{array}$ & $\begin{array}{c}0.06905 \\
.\end{array}$ & \\
\hline DE 5 & $\begin{array}{c}-0.00055 \\
(-9.21)\end{array}$ & $\begin{array}{c}-0.06980 \\
(-10.94)\end{array}$ & . & $\begin{array}{c}0.09775 \\
.\end{array}$ & 1,316 \\
\hline \multirow[t]{2}{*}{ DE 6} & $\begin{array}{c}-0.00058 \\
(-9.57) \\
\end{array}$ & $\begin{array}{c}-0.08210 \\
(-5.27) \\
\end{array}$ & $\begin{array}{r}0.10360 \\
(14.26) \\
\end{array}$ & 0.16305 & 1,288 \\
\hline & \multicolumn{4}{|c|}{ Panel C. For each analyst and firm } & \\
\hline DE 7 & $\begin{array}{c}-0.00050 \\
(-14.03)\end{array}$ & . & $\begin{array}{c}0.01404 \\
(4.28)\end{array}$ & 0.08207 & 7,185 \\
\hline DE 8 & $\begin{array}{c}-0.00050 \\
(-10.53)\end{array}$ & $\begin{array}{c}-0.07970 \\
(-23.35)\end{array}$ & . & 0.13084 & 7,267 \\
\hline DE 9 & $\begin{array}{c}-0.00040 \\
(-1.89)\end{array}$ & $\begin{array}{c}-0.08630 \\
(-15.83) \\
\end{array}$ & $\begin{array}{c}0.01996 \\
(5.42) \\
\end{array}$ & $\begin{array}{c}0.20758 \\
.\end{array}$ & 7,047 \\
\hline
\end{tabular}

TABLE 5

TEST OF RATIONALITY AS REVEALED BY ANALYSTS' FORECAST DEVIATIONS FROM CONSENSUS (FOUR PERIOD-SECTOR COMBINATIONS)

The term ${ }_{t} F E_{j, t+1}^{k}$ is the forecast error made by analyst $j$ at time $t$, for the earnings of firm $k$ at time $t+1$. Similarly, ${ }_{t} D E_{j, t+1}^{k}$ is the deviation of forecast number from the consensus estimate made by analyst $j$ at time $t$, for the earnings of firm $k$ at time $t+1$. (See definitions of $F E$ 's and $D E$ 's in the notes for Table 1.) The values of t-ratio are in the parentheses under coefficients. The term $\mu$ is the mean of $F E_{j, t+1}^{k}$, while $v$ is the mean of ${ }_{t} D E_{j, t+1}^{k}$. The terms $\gamma_{1}$ and $\gamma$ ${ }_{2}$ are regression parameters. The numbers of analyst-firm pairs used in the estimation of the parameters are listed as $\mathrm{N}$ on the last column of the table.

\begin{tabular}{|c|c|c|c|c|c|c|}
\hline \multicolumn{7}{|c|}{ Model DE9: ${ }_{t} D E_{j, t+1}^{k}=v\left(1-\gamma_{2}\right)+\gamma_{1}\left({ }_{t-1} F E_{j, t}^{k}-\mu\right)+\gamma_{2}{ }_{t-1} D E$} \\
\hline \multicolumn{7}{|c|}{ Average across all analyst-firm pairs } \\
\hline Period & Sector & $v$ & $\gamma_{1}$ & $\gamma_{2}$ & $\mathrm{R}^{2}$ & $\mathrm{~N}$ \\
\hline \multirow{2}{*}{ 1992-1999 } & Non-high-tech & $\begin{array}{c}-0.00040 \\
(-1.89)\end{array}$ & $\begin{array}{c}-0.08630 \\
(-15.83)\end{array}$ & $\begin{array}{c}0.01996 \\
(5.42)\end{array}$ & 0.21 & 7,047 \\
\hline & High-tech & $\begin{array}{r}-0.00060 \\
(-10.89)\end{array}$ & $\begin{array}{c}-0.16190 \\
(-6.20)\end{array}$ & $\begin{array}{c}-0.00249 \\
(-0.35)\end{array}$ & 0.26 & 2,188 \\
\hline \multirow{2}{*}{$2000-2007$} & Non-high-tech & $\begin{array}{c}-0.00040 \\
(-2.03)\end{array}$ & $\begin{array}{c}-0.06230 \\
(-12.65)\end{array}$ & $\begin{array}{c}-0.00935 \\
(-2.63)\end{array}$ & 0.20 & 7,710 \\
\hline & High-tech & $\begin{array}{c}-0.00022 \\
(-4.03)\end{array}$ & $\begin{array}{c}-0.07110 \\
(-8.87)\end{array}$ & $\begin{array}{c}0.00651 \\
(1.23)\end{array}$ & 0.22 & 3,541 \\
\hline
\end{tabular}




\section{Correlation Analysis}

The vast amount of parameter estimates from each of the six models, FE7, FE8, FE9, DE7, DE8, and DE9, at both analyst and firm levels, need to be integrated into a compact framework from which one may extract a bird-eye's view. Take, as an example, the two parameters $\mu$ and $\alpha_{1}$, each representing a rationality condition. How well an analyst performs in forecasting depends not only on each of the two aspects of the rationality, but also the interactions between the two. A question which is often raised is: "To achieve better performance, should an analyst work more on timely and accurate information collection (by accessing corporate executives) or on unbiasedness (without relying on favors from corporate management), or a combination of the two as dictated by factors related to the firms?" This is an important practical question. A correlation analysis on the two parameter estimates can help provide better understanding of the nature and characteristics of interactions among various aspects of analysts' performance and between analysts and the firms that they follow. Such understanding helps suggest answers to the question posted above.

Analyses on each of the six models mentioned above were carried out by the authors. In the interest of space economy and presentational conciseness, we present only the results for the main complete case of Model FE9 in this subsection, while details of analyses on other models are available from the authors. As such, we display in Table 6 pair-wise correlation coefficients for Model FE9 at the analyst and the firm level separately. The results for analysts are presented in Panel A, while those of firms are in Panel B. Each pair-wise correlation coefficient is based on a pair of the parameter estimates, one for each analyst-firm combination, in Model FE9.

In Table 6, we note that the correlation coefficient $\rho_{\mu_{j}, \alpha_{1, j}}$ for 1992-1999 non-high-tech firms is computed based on 1,312 pairs of parameter estimates of $\mu_{j}$ and $\alpha_{1, j}$, one pair for each analyst $\mathrm{j}$. The result, as displayed on the first line of Panel A, is equal to 0.01695 , with a p-value of 0.5414 . This suggests that the two parameters (bias and the first-lag serial correlation of forecast errors) are not significantly correlated at the analyst level. In other words, there is no statistically verifiable association between analysts' propensity of optimism/pessimism and their tendency of under- or over-reaction to previous forecast errors.

But the same correlation coefficient at the firm level for 1992-1999 non-high-tech firms, displayed on the first line of Panel B, tells a drastically different story. The value of the coefficient $\rho_{\mu_{k}, \alpha_{1, k}}$, based on 984 pairs of estimates, is equal to 0.15898 , providing a p-value of less than 0.0001 , which clearly signals a positive relation between the bias of forecasts and the serial correlation of forecast errors at the firm level. It means that, over a substantial period of time (or the life time of a firm, up to 8 years as in our sample for 1992-1999), those firms, which are often hit with very large earnings disappointments (hence large positive ex post forecast errors) are also the ones which analysts, on average, under-react the most to (having a large positive $\alpha_{1}$ value). On the other hand, those firms with the largest positive earnings surprises (large negative ex post forecast errors) over time are the ones bringing in strongest overreactions from analysts (having a large negative $\alpha_{1}$ value).

This finding, as just stated, is strikingly consistent with the finding reported in the study by Easterwood and Nutt (1999); which demonstrates that analysts, as represented by their consensus forecasts, tend to under-react to bad earnings news and overreact to good earnings news. Easterwood and Nutt (1999) interpret the phenomenon as an example of analysts' tendency of "systematic optimism". But as we have noted above, the phenomenon is a "firm" effect, which takes place in the absence of an "analyst" effect. It means that our finding suggests that a significant and peculiar interaction exists between analysts and the firms that they follow, in the fashion as we have described above, independent of an analyst's propensity toward optimism or pessimism. It would be incorrect to infer from this phenomenon that analysts in general are "over-optimistic". As we have reported earlier, from a direct observation of analysts' behaviors, about half of the analysts in our sample are not over-optimists. In the 1992-1999 non-high-tech firms, the four percent of suspected "hardcore" over-optimistic analysts as 
reported in a previous section would not conceivably be able to engender such a strong and systematic phenomenon on both good news and bad news firms. Even more interestingly, analysts' asymmetric irrationality (more optimists than pessimists) can be integrated into this "firm effect", to form a potential resolution to a key aspect of the long-debated stock price return anomaly known as the "post-earningsannouncements price drift". This phenomenon appeared to taper off somewhat in the post-2000 period, for both non-high-tech and high-tech firms.

We now turn our attention to the correlation coefficient. The calculated value of $\rho_{\mu_{j}, \alpha_{2, j}}$, for 19921999 high-tech firms, based on 595 analysts, is equal to -0.10970 and has a p-value of 0.0080 . It suggests a strong negative relation between the two parameters. It means that an analyst who has a strong negative feedback from the lagged DE's to FE's tends to also have a strong positive forecast bias. This is an interesting observation. It implies that an over-optimistic analyst tends to be a sensitive opinion watcher. When his forecast was much higher (lower) than the consensus in the previous period, he tends to steer in the opposite direction to moderate his forecast error in the next period. But overall, he still overshoots. On the other hand, an over-pessimistic analyst tends to maintain his position and not steer around his next forecast based on his deviation from the consensus in this quarter. This provides a useful insight into how analysts, with different attitudes, behave in earnings forecasting. Interestingly, analysts for non-high-tech firms tend to behave, though marginally significantly, in the opposite way, that is, to have positive value of $\rho_{\mu_{j}, \alpha_{2, j}}$. The end of the high-tech stock market boom did not appear to change these features.

When moving down to the firm level, as shown in Table 6, Panel B, on the middle column, we see that the relation between $\mu_{k}$ and $\alpha_{2, k}$ in model FE9 is strongly positive for non-high-tech firms and strongly negative for high-tech firms. Both were not much affected by the ending of the high-tech stock market boom. These results reconfirm the strength of the phenomenon described in the immediately preceding paragraph.

In summary, we note that the correlation coefficients $\rho_{\mu_{j}, \alpha_{2, j}}$ and $\rho_{\mu_{k}, \alpha_{2, k}}$ exhibit two contrasting behavioral patterns in analysts' forecasting in high-tech versus non-high-tech firms. For high-tech firms, optimistic analysts appear to be sensitive to consensus forecasts and tend to steer toward the "norm", by chasing the herd. On the other hand, pessimistic analysts seem to hold their ground; firmly staying on course and ignoring the herd. But for non-high-tech firms, optimistic analysts behave as if they held firm convictions on their own and are not to be swayed by the consensus. In contrast, pessimistic analysts for non-high-tech firms seem opt to be herd followers steering toward the consensus. These behaviors stay unchanged in the post-2000 period. These observations raise an interesting question: "Are there more uncertainty on upside for high-tech firms and downside for non-high-tech firms, relative to the other side, that make analysts more nervous and look to the consensus for guidance?" Further work is needed to answer the question.

The correlation coefficients between $\alpha_{1, j}$ and $\alpha_{2, j}$ are, mostly, significantly negative for the $2 \times 2$ categories, as shown on the rightmost column on Panel A. The correlation coefficients between $\alpha_{1, k}$ and $\alpha_{2, k}$ are even more significantly negative, for the $2 \times 2$ categories, as shown on the rightmost column on Panel B. This means that negative $\alpha_{2}$ (herd follower) tends to go with positive $\alpha_{1}$ (under-reaction). This implies that herd followers tend to be slow movers in reacting to previous forecast errors (because they are not confident on what they predict). This seems to be intuitively understandable and appealing. 


\section{TABLE 6}

\section{CORRELATION OF PARAMETER VALUES IN TWO-WAY FIXED EFFECT ANALYSIS}

This table displays correlation coefficients computed for various pairs of parameter values specified in the two-way fixed effect analysis for Model FE9. The results are tabulated at both the analyst and the firm level. Explanations for the notations herein can be found in pervious tables. The p-value of each of the estimated correlation coefficient is placed in the parentheses underneath. The number of data points is designated as " $n$ " in the parentheses beneath the period/sector caption.

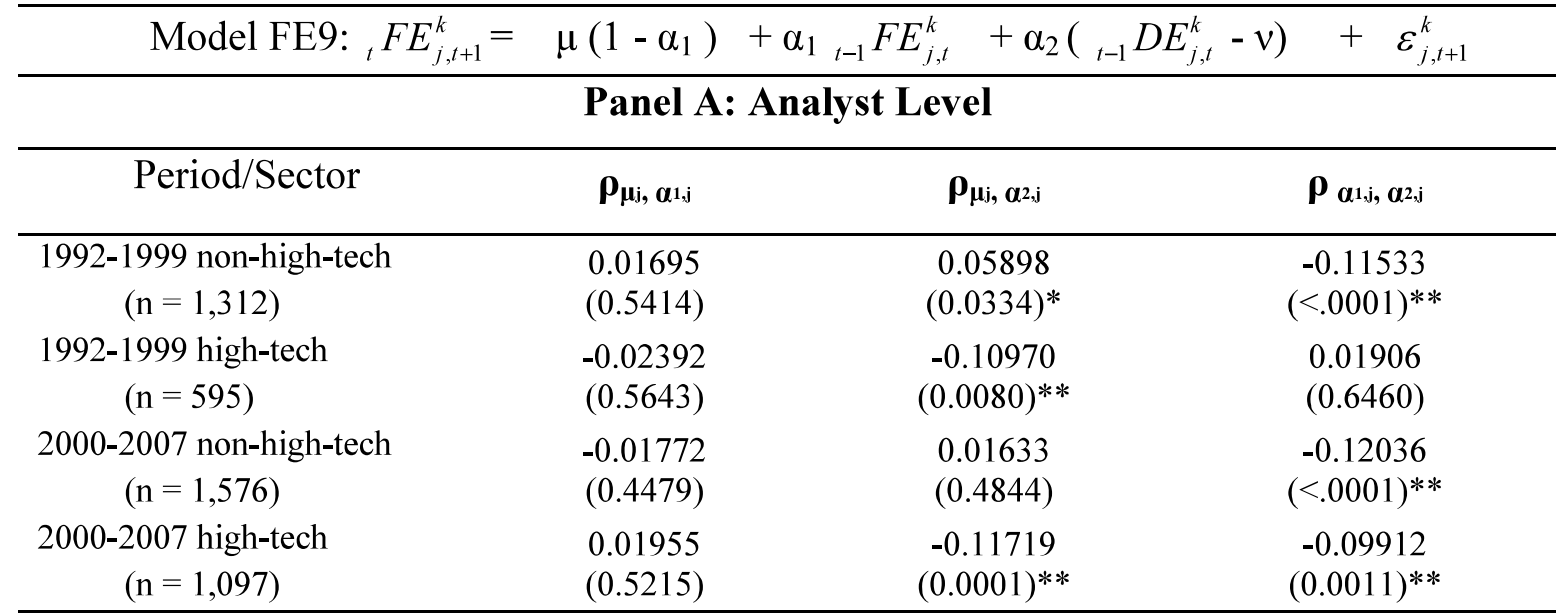

\section{Panel B: Firm Level}

\begin{tabular}{cccc}
\hline Period/Sector & $\boldsymbol{\rho}_{\boldsymbol{\mu k}, \boldsymbol{\alpha}, \mathbf{k}}$ & $\boldsymbol{\rho}_{\boldsymbol{\mu k}, \boldsymbol{\alpha}, \mathbf{k}}$ & $\boldsymbol{\rho}_{\boldsymbol{\alpha} 1, \mathbf{k}, \boldsymbol{\alpha} 2, \mathbf{k}}$ \\
\hline 1992-1999 non-high-tech & 0.15898 & 0.09317 & -0.17640 \\
(n=984) & $(<.0001)^{* *}$ & $(0.0036)^{* *}$ & $(<.0001)^{* *}$ \\
1992-1999 high-tech & 0.13469 & -0.15003 & -0.13821 \\
(n = 311) & $(0.0188)^{*}$ & $(0.0088)^{* *}$ & $(0.0159)^{*}$ \\
2000-2007 non-high-tech & -0.08385 & 0.39926 & -0.19870 \\
(n= 925) & $(0.0110)^{*}$ & $(<.0001)^{* *}$ & $(<.0001)^{* *}$ \\
2000-2007 high-tech & 0.08973 & -0.13597 & -0.17817 \\
(n= 405) & $(0.0727)$ & $(0.0064)^{* *}$ & $(0.0003)^{* *}$ \\
\hline
\end{tabular}

*denotes significance at the two-sided $5 \%$ level.

** denotes significance at the two-sided $1 \%$ level.

\section{Effects of New Governmental Regulations}

One would suspect that Regulation Fair Disclosure taking effect in August 2000 and Sarbanes-Oxley Act enacted in July 2002 may also play a role in analysts' behavioral changes in the post-2000 period. Regulation Fair Disclosure may have reduced analysts' incentives to curry favors with the firms they follow, hence have curbed their tendency to over-estimate the firms' earnings. But it does not explain why analysts would have gone to the extent to systematically under-estimate in the post-2000 era, especially in the high tech sector. Further, Sarbanes-Oxley Act is designed to deter corporations from falsifying or omitting material information in accounting statements. It may have reduced corporations' frequency and extent of earnings management in the post-2000 period, especially in over-reporting or inflating earnings numbers. It should hence reduce cases of extreme earnings disappointments (due to previous accumulated chronic over-reporting and eventual revelations of the extent of true deficit) and help analysts become less upwardly biased, ex post. For that reason, analysts should rest assured that a pre-emptive markdown in their earnings estimates would not be necessary. But what we have observed in our analysis instead is that analysts tended to multiply in their mark-downs and systematically underestimate earnings for firms in 
the high tech sector in the post-2000 period. This does not appear to be the outcome one would reasonably expect from Sarbanes-Oxley Act. We thus feel that the phenomena reported in this paper cannot be significantly driven by the two sets of governmental regulations enacted in early 2000 's.

\section{Summary of Findings and Concluding Remarks}

In this paper we report findings which clarify the nature and characteristics of analysts' earnings forecast errors, the dynamics behind the shifts of analysts' mentality, and their use of strategies in the wake of the abrupt ending of the high-tech stock market bubble in early year 2000 .

The main findings are summarized below.

The distributions of analysts' earnings forecast errors, when compiled by analysts, during the pre2000 period, are found to be biased to the upside in part due to a small number of extremely optimistic forecasts. However, after the abrupt ending of the high-tech market boom, the forecasting error distribution of high-tech stocks, compiled by analysts, shifts strongly to the down side with the magnitude of the pessimistic bias rising very sharply. When the frequency tabulation is done on a firm-by-firm basis for the high-tech firms, the swing of the error distribution to the left becomes extreme.

The slowness or lethargy of analysts' reaction to previous forecasting errors, as measured by the parameter $\alpha_{1}$, is found to lean moderately toward the positive side, meaning an under-reaction. This phenomenon applies to both high-tech and non-high-tech firms, while it shows a moderate improvement moving toward the zero value for both sectors during the post-2000 period.

The lagged DE variable tends to negatively affect FE (carrying negative regression coefficient) for the pre-2000 period, for both high-tech and non-high-tech sectors. However, this effect disappears in the post-2000 period for the high-tech sector. This hints at the abatement of analysts' herding mentality in the post-boom period.

The correlation between analysts' upward bias and under-reaction in earnings forecasts is found to be strong during the pre-2000 period, compiled on a firm-by-firm basis. But it reverses for the non-high-tech sector, and turns insignificant for the high-tech sector, during the post-2000 period.

The correlation between forecast bias and lagged effect of DE on FE is found to be positive for nonhigh-tech firms, and negative for high-tech firms, but is little affected by the end of high-tech market boom. It is also found that the two parameters, $\alpha_{1}$ and $\alpha_{2}$, are, in general, negatively related, indicating that herd followers tend to under-react to previous forecast errors.

Overall, we note that the factors embedded in a specific firm affect forecast errors more than the factors attributable to individual analysts. Further, a drastic change in market conditions can force analysts to learn from their mistakes or biases and to markedly alter their mentalities, attitudes, strategies, and hence improve (though could over-correct as well) their forecast performance.

As we have indicated in previous sections, knowledge about the interactions between analysts and factors embedded in the firms followed by the analysts is important in understanding analysts' behaviors in earnings forecasting. The scope and strength of the analyses reported in this study is significantly constrained by the lack of randomization of the analyst-firm pairing. We also recognize that the procedure to standardize forecast errors, using de-trended per share stock price, is not without shortcomings. Improvements on these aspects of the study are for future research work.

One notion we have stressed throughout this paper is that different individual analysts possess different behavioral patterns and mentalities. Their interactions with the firms which they follow are varied, diverse and dynamic. We cannot assume analysts' behaviors to stay steady for an extensive period of time.

The concept of instability in the structure of financial models and in market participants' behaviors over time, along with the methodologies developed in this paper, the current authors believe, will have applications and implications to research in a wide range of other financial subjects. 


\section{REFERENCES}

Abarbanell, J.S., \& Lehavy, R. (2003). Biased forecasts or biased earnings? The role of reported earnings in explaining apparent bias and over/under reaction in analysts' earnings forecasts. $J$ Account Econ, 36, 105-146.

Bergstresser, D., \& Philippon, T. (2006). CEO incentives and earnings management. J Financial Econ, 80, 511-529.

Bernhardt, D., Campello, M., \& Kutsoati, E. (2006). Who herds? J Financial Econ, 80, 657-675.

Brown, L.D. (1997). Analyst forecasting errors: Additional evidence. Financial Analyst J, 53 (November/December), 81-88.

Cassidy, J. (2002). dot.con - The greatest story ever sold. New York, NY: HarperCollins Publishers.

Chen, Q., \& Jiang, W. (2006). Analysts' weighting of private and public information. Rev Financial Studies, 19, 319-355.

Clarke, J., \& Subramanian, A. (2006). Dynamic forecasting behavior by analysts: Theory and evidence. $J$ Financial Econ, 80, 81-113.

Clement, M.B., \& Tse, S.Y. (2005). Financial analyst characteristics and herding behavior in forecasting. $J$ Finance, 60, 307-341.

Copeland, T., Dolgoff, A., \& Moel, A. (2004). The role of expectations in explaining the cross-section of stock returns. Rev Account Studies, 9, 149-188.

Cooper, R.A., Day, T.A., \& Lewis, C.M. (2001). Following the leader: A study of individual analysts' earnings forecasts. J Financial Econ, 61, 383-416.

De Bondt, W.F.M., \& Thaler, R.H. (1990). Do security analysts overreact? American Econ Rev, 80, 5257.

Dechow, P.M., Hutton, A.P., \& Sloan, R.G. (2000). The relation between analysts' forecasts of long-term earnings growth and stock price performance following equity offerings. Contemporary Account Res, 17, 1-32.

Dichev, I., Graham, J., Harvey, C.R., \& Rajgopal, S. (2012). Earnings quality: Evidence from the field. Social Science Research Network (SSRN) paper \#2103384:1-74

Diether, K.B., Malloy, C.J., \& Scherbina, A. (2002). Differences of opinion and the cross section of stock returns. J Finance, 57, 2113-2141.

Easterwood, J.C., \& Nutt, S.R. (1999). Inefficiency in analysts' earnings forecasts: Systematic misreaction or systematic optimism? J Finance, 54, 1777-1797.

El-Galfy, A.M., \& Forbes, W.P. (2004). Are forecasts of corporate profits rational? A note and further evidence. J Empirical Finance, 11, 617-626.

Fama, E.F. (1998). Market efficiency, long-term returns, and behavioral finance. J Financial Econ, 49, 283-306.

Greene, W.H. (2003). Econometric analysis, $5^{\text {th }}$ ed. Upper Saddle River, NJ: Prentice Hall.

Hong, H., \& Kubik, J.D. (2003). Analyzing the analysts: Career concerns and biased earnings forecasts. J Finance, 58, 313-351.

Hong, H., Kubik, J.D., \& Solomon, A. (2000). Security analysts' career concerns and the herding of earnings forecasts. RAND J Econ, 31, 121-144.

Keane, M.P., \& Runkle, D.E. (1990). Testing the rationality of price forecasts: New evidence from panel data. American Econ Rev, 80, 714-735.

Keane, M.P., \& Runkle, D.E. (1998). Are financial analysts' forecasts of corporate profits rational? $J$ Political Economy, 106, 768-804.

Knill, A., Minnick, K., \& Nejadmalayeri, A. (2012). Experience, information asymmetry, and rational forecast bias. Rev Quant Finance Account, 39, 241-272.

Lim, T. (2001). Rationality and analysts' forecast bias. J Finance, 56, 369-385.

Michaely, R., \& Womack, K. (1999). Conflict of interest and the credibility of underwriter analyst recommendations. Rev Financial Studies, 12, 653-686. 
Shleifer, A. (2000). Inefficient markets - An introduction to behavioral finance. London, U.K.: Oxford University Press.

Stickel, S.E. (1991). Common stock returns surrounding earnings forecast revisions: More puzzling evidence. Account Rev, 66, 402-416.

Stickel, S.E. (1992). Reputation and performance among security analysts. J Finance, 47, 1811-1836.

Tamura, H. (2002). Individual-analyst characteristics and forecast error. Financial Analysts J, 58, (July/August): 28-35.

Welch, I. (2000). Herding among security analysts. J Financial Econ, 58, 369-396.

$\mathrm{Xu}, \mathrm{L} ., \quad \&$ Tang, A.P. (2012). Internal control material weakness, analysts' accuracy and bias, and brokerage reputation. Rev Quant Finance Account, 39, $27-53$.

Zitzewitz, E. (2001a). Measuring herding and exaggeration by equity analysts and other opinion sellers. Stanford University GSB Working Paper.

Zitzewitz, E. (2001b). Opinion-producing agents: Career concerns and exaggeration. Stanford University GSB Working Paper. 